doi: $10.15407 /$ ujpe62.07.0625

I.I. GRYGORCHAK, ${ }^{1}$ O.I. HRYHORCHAK, ${ }^{2}$ F.O. IVASHCHYSHYN ${ }^{1}$

1 National University "Lviv Polytechnic"

(12, S. Bandera Str., Lviv 79013, Ukraine; e-mail: ivan_gryg@ukr.net, fivash@i.ua)

2 Ivan Franko National University of Lviv

(12, Dragomanov Str., Lviv 79005, Ukraine; e-mail: HrOrest@gmail.com)

\title{
MODIFICATION OF THE PROPERTIES
}

OF InSe $\left\langle\beta\right.$-CD $\left.\left\langle\mathrm{FeSO}_{4}\right\rangle\right\rangle$ CLATHRATE/CAVITATE

COMPLEXES WITH HIERARCHICAL ARCHITECTURE

PACS 62.23.St, 73.63.-b,

81.16.-c, 75.75.-c,

81.07.Bc, 81.07.Pr

\section{AT THEIR SYNTHESIS IN CROSSED ELECTRIC AND LIGHT-WAVE FIELDS}

\begin{abstract}
A new technological approach is proposed for the synthesis of multilayered nanostructures, which provides them unique properties and extraordinary prospects of practical applications. In particular, the synthesis of the InSe $\left\langle\beta-C D\left\langle F e S O_{4}\right\rangle\right\rangle$ nanostructure with hierarchical architecture in crossed electric and light-wave fields is shown to result in the abnormally strong positive magnetoresistance effect with giant magnetoresistance oscillations in a low-frequency interval of $10^{-3}-10 \mathrm{~Hz}$. The efficiency of applying the synthesized nanohybrid as an active element in gyrator-free delay nanolines controlled by the magnetic field and in magnetic-field sensors that are supersensitive at room temperatures is substantiated.
\end{abstract}

Ke y words: InSe, intercalation, clathrate, cavitand, cavitate, hierarchical structures, impedance spectroscopy, magnetoresistive effect.

\section{Introduction}

For more than a decade, the enhanced attention has been attracted to the formation of nanohybrid inorganic/organic composites. They are considered as an attempt to obtain structures with a wide spectrum of new properties remaining unknown till now $[1,2]$. The progress reached on the way of their practical application cannot be considered impressing. However, only the first steps along this way were made, so that the accumulated experience is insignificant [3$5]$. It seems that a further progress in the comprehensive study of such nanohybrids aimed at expanding the scope of their practical application can be reached by using supramolecular objects as a guest content, which are often associated with a possi-

(C) I.I. GRYGORCHAK, O.I. HRYHORCHAK, F.O. IVASHCHYSHYN, 2017

ISSN 2071-0194. Ukr. J. Phys. 2017. Vol. 62, No. 7 bility to realize unique, often paradoxical, physicochemical properties [6]. Their receptor (a "host") contains molecular centers adjusted to selectively bind a definite substance (a "guest") following the so-called "lock-key" mechanism. One of their variety is responsible for a new principle of medium organization, clathrate. Evidently, this approach makes it possible to form supramolecular ensembles with hierarchical architecture subhost $\langle$ host $\langle$ guest $\rangle\rangle$. It is anticipated that the latter can make a sound contribution to the development of nanoengineering.

In works [7, 8], we used 18-crown-ether-6 $\left(\mathrm{C}_{12} \mathrm{H}_{24} \mathrm{O}_{6}\right)$ and thiourea (thiocarbamide $\left.\mathrm{CS}\left(\mathrm{NH}_{2}\right)_{3}\right)$, respectively, as guest cavitands. It was proved that the synthesized clathrate/cavitand ensembles of the former type are promising for the development of supramolecular photoelectronics, and those of the latter type to enhance the efficiency of the $\mathrm{Li}^{+}$- interca- 
lation current generation. Recently [9], we have synthesized a supramolecular ensemble with essentially new architecture subhost $\langle$ host $\langle$ guest $\rangle\rangle$, in which the organic/inorganic cavitate of $\beta$-cyclodextrin $(\beta$-CD) and iron sulfate served as a guest content in the inorganic $\mathrm{SiO}_{2}$ submatrix MCM-41, thus forming a guest hierarchy. It is in this ensemble where the colossal magnetocapacitance effect and the giant (almost tenfold) alternating-current (in a frequency interval of $10^{3}-10^{6} \mathrm{~Hz}$ ) negative magnetoresistive effect taking place under room temperatures and weak magnetic fields were revealed for the first time.

Unfortunately, another opportunity to increase the variability of required properties of produced inorganic/organic nanohybrids still remains beyond attention. This is the synthesis of nanohybrids in external physical fields such as magnetic, electric, and light-wave ones. Since information concerning this research direction is absent altogether, the aim of this work was to fill, at least partially, the corresponding lacuna.

\section{Experimental Materials and Research Methods}

In view of the permanently growing interest to nanophotoelectronics and quantum-mechanical coherent spintronics, we selected photosensitive semiconducting quasi-two-dimensional indium selenide (InSe) as a matrix-subhost. On the basis of this compound, we synthesized clathrates with hierarchical architecture $\operatorname{InSe}\left\langle\beta-\mathrm{CD}\left\langle\mathrm{FeSO}_{4}\right\rangle\right\rangle$ formed by encapsulating the guest contents of the "host-guest" type.

InSe single crystals were grown, by using the Bridgman-Stockbarger method, and had a well-pronounced layered structure and the conductivity of the $n$-type. The energy gap width (according to optical data) amounted to $1.2 \mathrm{eV}$. It is well known [10] that InSe single crystals are characterized by the presence of the so-called "guest" positions. These regions are oriented normally to the crystallographic axis $C$, in which the van der Waals forces are weak. The insertion of foreign atoms into indicated intracrystalline voids is known as the intercalation phenomenon [11]. The absence of dangling bonds at surfaces is responsible for a very low rate of surface recombination. Moreover, single crystals are characterized by a high photosensitivity in the visible spectral interval. The organic cavitand $\beta$-cyclodextrin $(\beta$-CD) was used as an intermediate host. Its unique structural feature, namely, the separation of hydrophylic and hydrophobic groups, is responsible for its unordinary physico-chemical properties. The most important of them is the ability to reversely and selectively bind organic, inorganic, and biological molecules by forming insertion complexes of the "lock-key" type. A high electron concentration in the $\beta$-CD cavity can activate electrons of "guest" molecules, which gives rise to a modification of spectral properties of both the inserted molecules and $\beta$-CD itself [12]. As a substrate, iron(II) sulfate was applied, which is known to be a precursor for synthesizing nanomagnetite, whose cation component has a large spin magnetic moment.

Neither $\beta$-cyclodextrin nor iron sulfate can be directly inserted into InSe. Therefore, in order to form supramolecular ensembles, we applied the threephase intercalation-deintercalation technology, which was described in our work [13] in detail. The method allowed us to reach a four-fold expansion of the initial matrix. In order to research the influence of an electric field and illumination imposed in the course of nanohybrid formation on the current flow and polarization properties, some of the structures were formed under teh action of a constant electric field $110 \mathrm{~V} / \mathrm{cm}$ in strength, which was directed perpendicularly to the nanolayers; simultaneously, the structures were integrally illuminated through a thermal filter. The precise gravimetric and chemical analyses were carried out at every stage.

The impedance measurements were performed in the direction of crystallographic axis $C$ in a frequency range of $10^{-3}-10^{6} \mathrm{~Hz}$ on a measuring complex "AUTOLAB" (ECO CHEMIE, the Netherlands) equipped with the software programs FRA-2 and GPES. Doubtful points were removed, by using the Dirichlet filter $[14,15]$. The frequency dependences of the complex impedance $Z$ were analyzed by the semigraphical method in the environment of the software package ZView 2.3 (Scribner Associates). The approximation errors did not exceed $4 \%$. The correspondence of the developed impedance models to the experimental data kit was confirmed by the absolutely stochastic character of the frequency dependences of the first-order residual differences $[14,15]$. The synthesized specimens were studied both under the illumination with visible light and in a $2.75-\mathrm{kOe}$ dc magnetic field directed perpendicularly to the nanolayers. 


\section{Results and Their Discussion}

Synthesis of $\operatorname{InSe}\left\langle\beta-\mathrm{CD}\left\langle\mathrm{FeSO}_{4}\right\rangle\right\rangle$ in the electric field under the simultaneous illumination with light gives rise to an essentially different behavior of the real component $\operatorname{Re} Z(\omega)$ of the complex impedance $Z(\omega)$ driven by delocalized carriers in the initial matrix, in comparison with the synthesis under normal conditions; namely, an insignificant recession against an almost fivefold growth, if comparing with the initial expanded matrix. The presence of trap centers in a vicinity of the Fermi level results in an appreciable contribution of hoppings over them to the ac conductance. As a result, in the whole examined $\omega$-region, one will observe a transformation of a point, which is an impedance image of the concentrated resistive element, into a curve in the complex impedance plane. This curve is the impedance image hodograph.

For $\mathrm{InSe}\left\langle\beta-\mathrm{CD}\left\langle\mathrm{FeSO}_{4}\right\rangle\right\rangle$ synthesized under normal conditions, the Nyquist diagram is a superposition of two arcs (Fig. 1). The higher-frequency one exhibits the current flow in non-intercalated nanolayers, and the lower-frequency arc through layers with the guest content. At the same time, the center of each arc is located below the axis of the real component of specific impedance, which points to the existence of a certain distribution of relaxation times. Its physical nature consists in that the indicated nano-sized layers of synthesized clathrate are characterized by complex conductivities. This is a result of localized states in a vicinity of the Fermi level in the former case and the fractal structure of the guest content in the latter one.

Under those conditions, let us take into account that $\operatorname{Re} Z(\omega) \rightarrow R_{0}$ at $\omega \rightarrow 0$. Then the impedance model structure will look like the equivalent circuit diagram shown in the inset in Fig. 1. Here, BCPE is a bounded constant phase element, whose impedance image in the complex impedance plane is given the expression

$Z_{\mathrm{BCP}}(j \omega)=A^{-1}(j \omega)^{-n} \tanh \left[R_{0} A(j \omega)^{n}\right]$,

where $A$ is a proportionality factor, $R_{0}$ the finitevalued resistance at the "zero" frequency, and $n$ the phase deviation indicator. The numerical parametric identification of the presented equivalent circuit diagram gives the following values: $n_{1}=0.46$ and $n_{2}=0.31$. The synthesis in the electric field under the simultaneous illumination transforms it into an arc, which is not terminated in the high-frequency

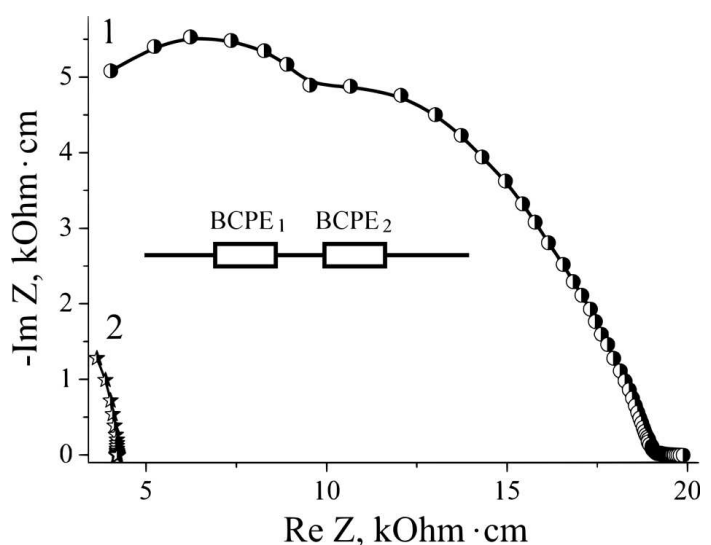

Fig. 1. Nyquist diagrams for the direction perpendicular to nanolayers in the initial clathrate $\operatorname{InSe}\left\langle\beta-\mathrm{CD}\left\langle\mathrm{FeSO}_{4}\right\rangle\right\rangle$ synthesized under the normal conditions (1) and in an electric field under the simultaneous illumination (2). Measurements were carried out under the normal conditions. The equivalent electric circuit for hodograph 1 is shown in the inset

(phonon) interval because of the restrictions inherent in technical capabilities of the applied measuring complex. Attention is attracted by an almost threefold reduction of $R_{0}$, which correlates well with the growth of the density of states at the Fermi level (Fig. 6).

The response of synthesized clathrates to a constant magnetic field applied perpendicularly to the nanolayers is accompanied by fundamental changes in the frequency dependences Re $Z(\omega)$ (Fig. 2) and the Nyquist diagrams (Fig. 3) for only the structures synthesized in the electric field under the simultaneous illumination. In particular, there appears a strong inductive response in the low-frequency interval, which is evidenced by the transition of the corresponding impedance hodograph branch into the IV-inductive quadrant of the complex plane. In this case, the magnetoresistive effect $\chi=\frac{\rho(H)}{\rho(0)}$ depends on the frequency (unlike the behavior of a nanohybrid synthesized under the normal conditions) and can reach an anomalous high value (almost by a factor of $10^{7}$ ) at room temperature.

It is well known $[16,17]$ that the frequency dependence of the real part $\sigma$ of the electric conductivity obeys the universal power law $\sigma(\omega)=A \omega^{s}$, where $A$ and $s$ are characteristic parameters. The latter serves for the identification of conductivity mechanisms in various materials [18]. As a rule, $0<s<1$ in the lowfrequency interval, and $s>1$ in the high-frequency 


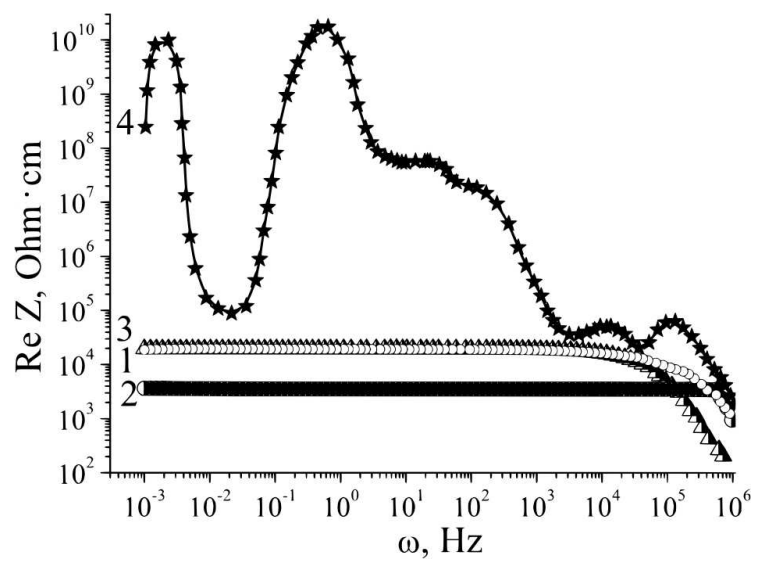

Fig. 2. Frequency dependences of the real component of the specific complex impedance measured in the direction perpendicular to nanolayers in the $\operatorname{InSe}\left\langle\beta-\mathrm{CD}\left\langle\mathrm{FeSO}_{4}\right\rangle\right\rangle$ clathrate synthesized under the normal conditions $(1,3)$ and in the electric field under the simultaneous illumination (2, 4). The dependences were measured in dark $(1,2)$ and in a magnetic field $(3,4))$

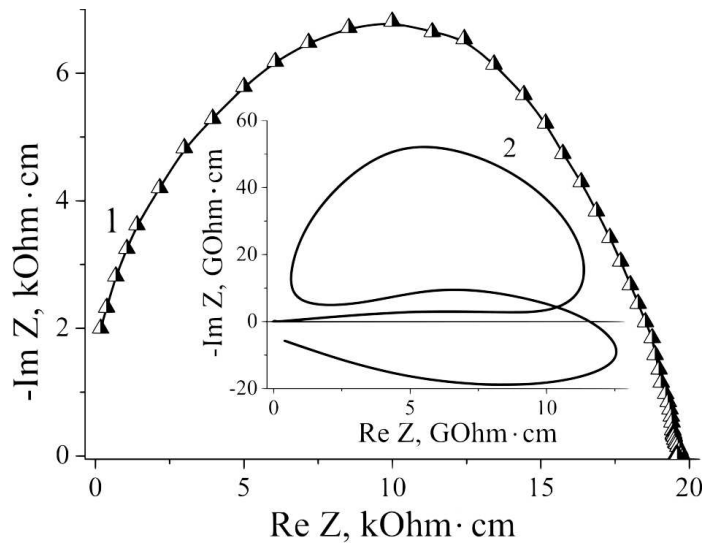

Fig. 3. Nyquist diagrams obtained in the magnetic field for the direction perpendicular to nanolayers in the InSe $\left\langle\beta-\mathrm{CD}\left\langle\mathrm{FeSO}_{4}\right\rangle\right\rangle$ clathrate synthesized under the normal conditions (1) and in the electric field under the simultaneous illumination (2)

one. The power-law dependence testifies to the hopping character of the current flow. The frequency dependence close to linear is usually associated with the electron hopping over localized states with the participation of phonons (the so-called relaxation hopping conductivity).

However, it can also be realized in the theory of low-temperature phononless (resonance) hopping conductivity, if the correlations of localized charge

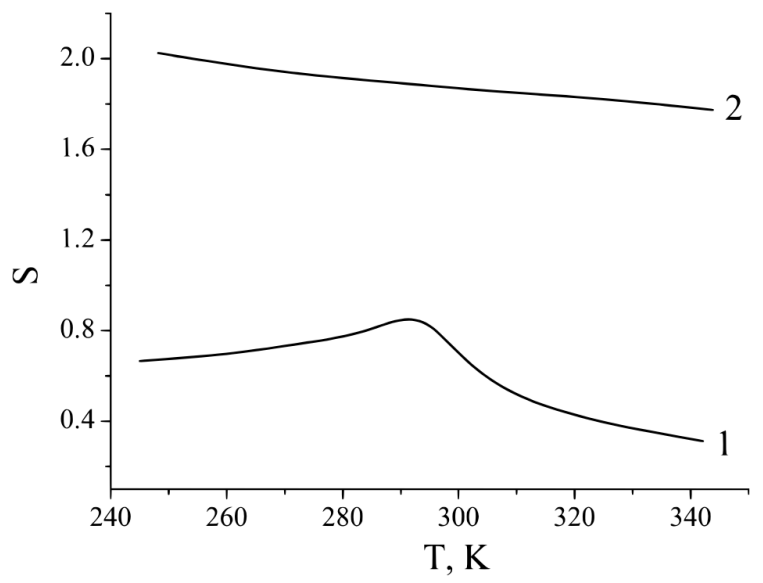

Fig. 4. Temperature dependences of $s$ in the low- (1) and high-frequency (2) intervals

carriers are taken into consideration [19]. The theory of phononless conductivity predicts a transition from the quasilinear conductivity to a sublinear one, i.e. close to quadratic $(s \approx 2)$, in the frequency interval, where $h \nu$ becomes comparable with the energy of the Coulomb interaction between electrons in resonance pairs. Since $s<1$ in our case, we will use other criteria, while specifying the hopping mechanism of current flow, namely, the character of the temperature dependence of $s$ [18]. It is easy to see that this parameter can be determined from the representation of experimental data in the coordinates $\ln [\sigma(\omega) A]$ versus $\ln (\omega)$ :

$s=\frac{\partial \ln [\sigma(\omega) A]}{\partial \ln (\omega)}$.

The results of calculation by formula (2) are depicted in Fig. 4. It is evident that, in general, the parameter $s$ is both temperature- and frequencydependent. In the latter case, two frequency intervals, in which this parameter is approximately constant, can be distinguished: $4 \times 10^{4}-2 \times 10^{5} \mathrm{~Hz}$ and $2 \times 10^{5}-$ $10^{6} \mathrm{~Hz}$.

Concerning the high-frequency interval, we may say about a single mechanism of phononless resonance hopping transport. However, at lower frequencies, we observe that the mechanisms change in a vicinity of $20{ }^{\circ} \mathrm{C}$. At low temperatures, the mechanism of quantum-mechanical tunneling is the most probable. As the temperature grows, it transforms into the phonon-assisted hopping over localized states near the Fermi level. In Fig. 5, the parameters of 

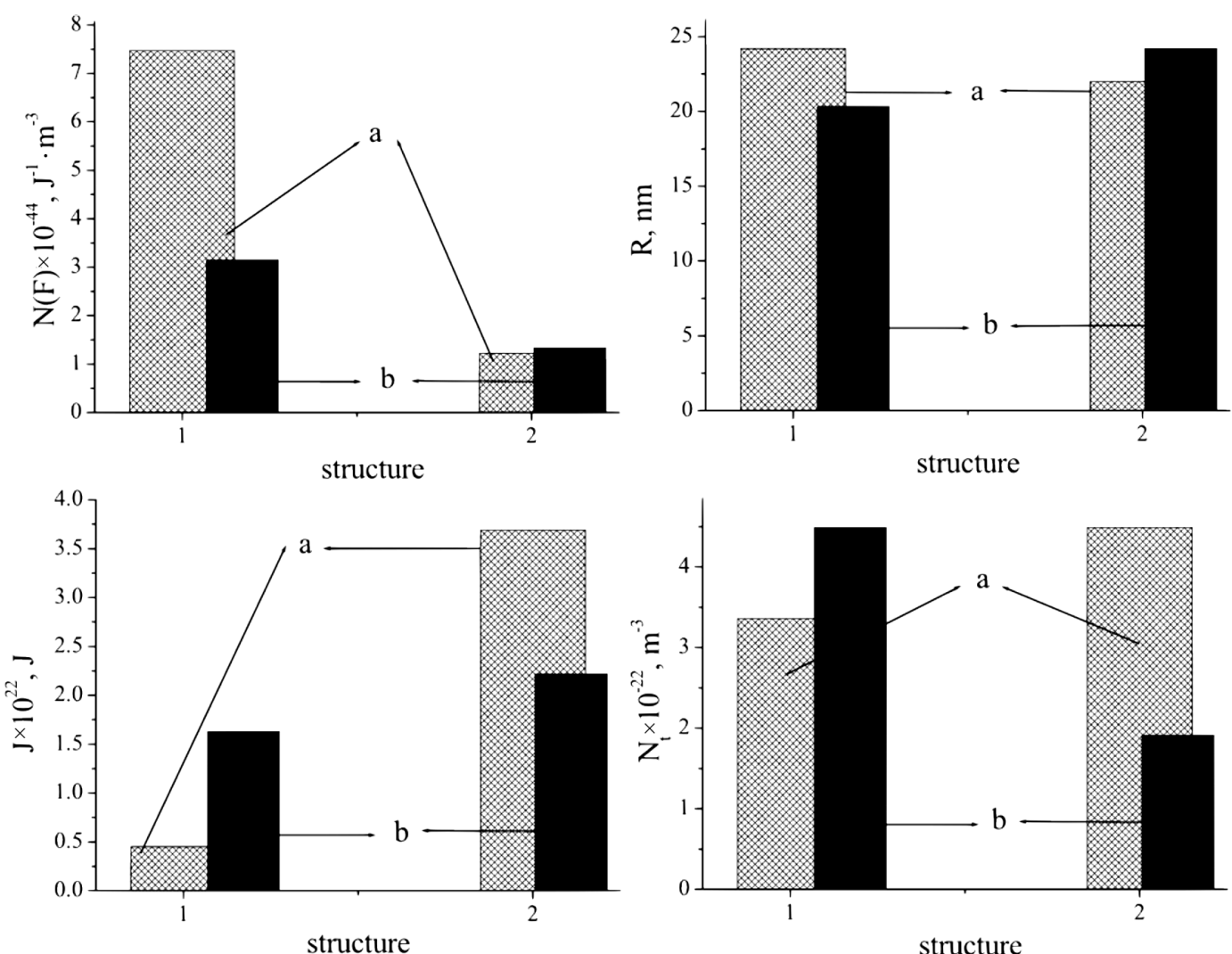

Fig. 5. Density of states at the Fermi level $(N(F))$, hopping length $(R)$, spread of trap states near the Fermi level $(J)$, and the actual density of deep traps $\left(N_{t}\right)$ for $\operatorname{InSe}\left\langle\beta\right.$-CD $\left.\left\langle\mathrm{FeSO}_{4}\right\rangle\right\rangle$ synthesized in the electric field under the simultaneous illumination (1) and under the normal conditions (2). Measurements in dark $(a)$ and in a magnetic field $(b)$

the impurity energy spectrum that characterize the hopping conductivity over localized states are shown; they were estimated according to work [20].

Really, as one can see from the presented data, the electret polarization formation at the synthesis provides an energy structure for impurity states in a vicinity of the Fermi level, which results in the strong Zeeman localization of charge carriers, a more than three-fold growth in the spread of trap states near the Fermi level, and a substantial growth of the actual deep trap concentration. It is hardly probable that the revealed colossal value of $\chi$ (Fig. 2) could be substantiated in the framework of spin-polarized transport mechanisms [21]. The assumption about a cardinal transformation of the energy topology for impurities, which governs the room-temperature conductivity of clathrate synthesized in external physical fields, seems to be more plausible. It is so, be- cause the imposing of the latter was aimed at the formation of a photo-electret state and, as a consequence, the creation of screening space charge layers. The latter, with regard for the multilayered character of the structure, should result in the splitting of the energy spectrum and the formation of its miniband character. From this viewpoint in view of the band-hopping origin of the current flow, one of the explanations of the colossal growth of Re $Z$ in the magnetic field consists in the Zeeman modification of the asymmetry in the density of states above and below the Fermi level. This localizes the Fermi level above the first completely filled subband and, in such a way, demonstrates a magnetically induced transition semiconductor-insulator.

The so-called negative capacitance effect was revealed (see hodograph 2 in Fig. 3). This phenomenon is known well enough from literature sources, because 


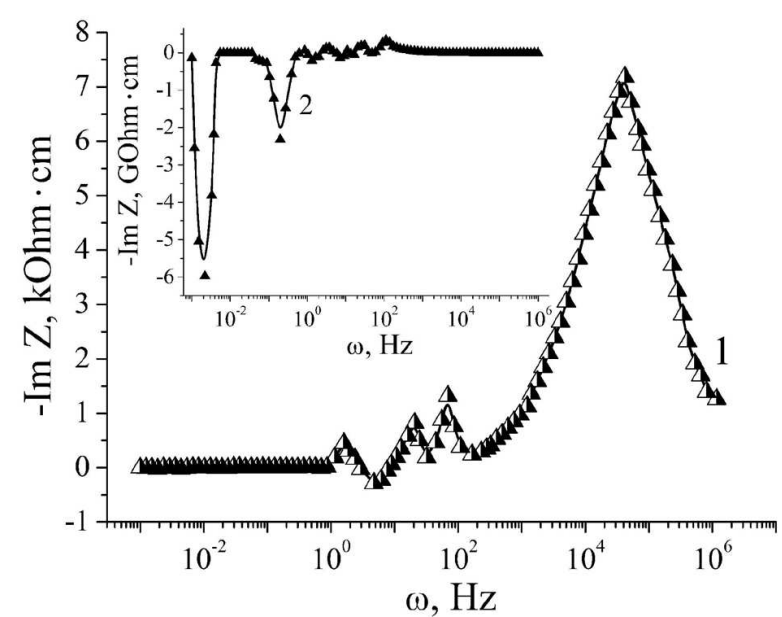

Fig. 6. Frequency dependences of the real component of the specific complex impedance measured in a magnetic field perpendicular to nanolayers in the $\operatorname{InSe}\left\langle\beta-\mathrm{CD}\left\langle\mathrm{FeSO}_{4}\right\rangle\right\rangle$ clathrate synthesized under the normal conditions (1) and in an electric field under the simultaneous illumination (2)

it can be used in nanoelectronics to create delay nanolines without gyrators. Its mechanism still has not been clarified at length, and there is an assumption that it has no definite nature [22-24]. In our case, its peculiarity consists in that its appearance is induced by a magnetic field. It should be noted that the observed hodograph loop (Fig. 2) follows from the oscillatory behavior of $\operatorname{Re} Z(\omega)$. At the same time, in the magnetic field, the frequency dependences $\operatorname{Im} Z(\omega)$ (Fig. 6) are also principally different for various synthesis conditions of the clathrate with hierarchical architecture $\operatorname{InSe}\left\langle\beta-\mathrm{CD}\left\langle\mathrm{FeSO}_{4}\right\rangle\right\rangle$.

Two important questions remain unanswered: Why does this effect in $\operatorname{InSe}\left\langle\beta-\mathrm{CD}\left\langle\mathrm{FeSO}_{4}\right\rangle\right\rangle$ arise due to the photo-electreting? Why can it be visualized only in the magnetic field? It is evident that, in order to give an ultimate answer concerning the origin of the observed phenomena, further comprehensive researches, both experimental and theoretical, are required. However, the available knowledge base in this domain makes it possible to mark some general reference points for the answer to those questions.

The formation of $\operatorname{InSe}\left\langle\beta-\mathrm{CD}\left\langle\mathrm{FeSO}_{4}\right\rangle\right\rangle$ includes two stages. At the first stage, the InSe crystalline matrix is expanded, and, at the second one, the guest content $\beta-\mathrm{CD}\left\langle\mathrm{FeSO}_{4}\right\rangle$ is inserted. In work [25], it was shown theoretically that the phase ordering changes the lattice period and reconstructs the Brillouin zone. As a result, the spectrum becomes split, and additional branches emerge. In their next work [26], on the basis of a model of the Anderson periodic model type, the cited authors calculated the density of states in the presence of a guest content. It was shown that, depending on its concentration and the value of electron impurity level, there may arise a pseudogap in the spectrum, with the depth of the corresponding minimum in the density of states being dependent on the indicated parameters. All that testifies to a complicated band structure of intercalates.

The synthesis of $\operatorname{InSe}\left\langle\beta-\mathrm{CD}\left\langle\mathrm{FeSO}_{4}\right\rangle\right\rangle$ in the electric field under the illumination introduces additional corrections into the material band structure. In particular, we may assume that, under those conditions, photo-electret states are formed and arranged in the energy gap in an appropriate way [27]. As a whole, this results in an increase of the Fermi level [28] and, accordingly, in the growth of the material conductivity. Just this behavior is observed in the experiment (curve 2 in Fig. 2). One can see that the real part of the impedance of a substance synthesized in the electric field under the illumination is several times smaller than that of the material synthesized under the normal conditions.

Can the behavior of this system in a magnetic field be predicted? Earlier, it was shown [29] that the magnetic field makes interband tunneling more complicated and, thus, reduces the material conductivity. Provided required parameters, the transition of charge carriers from the valence band or the impurity subbands into the conduction band can be essentially complicated. Moreover, the magnetic field diminishes the mobility for the majority of charge carriers. This fact can explain the substantial growth of the real part of the impedance in the low-frequency interval (curve 4 in Fig. 2). At higher frequencies, this effect competes with the frequency-stimulated interband tunneling; and the latter wins at a certain frequency. Then the following question arises: Why has the magnetic field practically no effect on the system synthesized under the normal conditions? Most probably, this is a result of the features in a modification of the electron spectrum at the photoelectreting. The formula describing the influence of the magnetic field on the interband tunneling intensity $[29,30]$ has an exponential form, in which the exponent is an expression depending on the distance between the energy bands, the magnetic field 
strength, and so on. Therefore, the conductivity of such systems at certain parameters (the magnetic field strength, effective electron mass, and others) is very sensitive to the band structure. This also means that this effect can disappear at higher or lower concentrations of the inserted guest content. A similar situation took place in our previous work [31].

Therefore, we may assume that the photo-electret synthesis of $\operatorname{InSe}\left\langle\beta-\mathrm{CD}\left\langle\mathrm{FeSO}_{4}\right\rangle\right\rangle$ provided existing parameters practically leads to the switching-off of the main mechanism of conductivity, so that our system becomes equivalent to an insulator in relation to it. This assumption is supplied by the behavior of the imaginary part of the impedance, which demonstrates a large inductive response of the system at frequencies, where the real component has maxima (see the inset in Fig. 6). This fact testifies to the dominating influence of deep trap centers on the conductivity in our system.

However, owing to the presence of photo-electret states, the mechanism of hopping conductivity has a substantial value. How can the magnetic field affect it? It is known that the magnetic field gives rise to the quantization of electron states and the formation of Landau levels. This can simulate the energy levels corresponding to different impurity states to approach one another and, accordingly, the hopping conductivity to increase, especially at frequencies coinciding with the frequencies of transitions between the Landau levels in impurity subbands. This model can explain the oscillation behavior of the real component of the impedance in the low-frequency interval (curve 4 in Fig. 2).

To explain the behavior of the indicated curves at a quantitative level, the microscopic approach is required, which is rather a laborious task. But it's worth it, because the importance of the proposed approaches for the technology of supersensitive magnetic field sensors and active elements of gyrator-free delay lines controlled by the magnetic field is undoubtful.

\section{Conclusions}

1. The synthesis of $\operatorname{InSe}\left\langle\beta-\mathrm{CD}\left\langle\mathrm{FeSO}_{4}\right\rangle\right\rangle$ in an electric field under the simultaneous illumination results in an essentially different variation character of the real component of the complex impedance, $\operatorname{Re} Z(\omega)$ associated with delocalized charge carriers in the initial matrix, in comparison with the case of $\mathrm{InSe}\left\langle\beta-\mathrm{CD}\left\langle\mathrm{FeSO}_{4}\right\rangle\right\rangle$ synthesis under the normal conditions. Namely, this is its insignificant recession in the former case in comparison with the almost fivefold growth in the latter one.

2. The response to a constant magnetic field applied normally to the nanolayers is accompanied by a cardinal transformation of the frequency dependences $\operatorname{Re} Z(\omega)$ and the Nyquist diagrams only for structures synthesized in the electric field under the simultaneous illumination. In particular, there appears a strong inductive response in the low-frequency interval. At the same time, unlike the behavior of a nanohybrid synthesized under the normal conditions, the magnetoresistive effect in this case depends on the frequency and can demonstrate an anomalous (almost $10^{7}$ ) growth at room temperature.

3. The formation of an electret polarization at the synthesis provides such an energy structure of impurity states in a vicinity of the Fermi level that stimulates more than the threefold growth of the trap state spread near the Fermi level and a substantial growth of the actual concentration of deep traps.

4. A feature of the "negative capacitance" effect observed at the $\mathrm{InSe}\left\langle\beta-\mathrm{CD}\left\langle\mathrm{FeSO}_{4}\right\rangle\right\rangle$ synthesis in an electric field under the simultaneous illumination consists in that its appearance is induced by the magnetic field.

5. The influence of the magnetic field gives rise to a reduction of the conductivity associated with delocalized charge carriers and a growth of the hopping conductivity, as well as to the quantization of energy levels of charge carriers, in particular, in impurity subbands, which can results in the oscillatory behavior of the real component of the impedance in the low-frequency interval.

1. J.H. Choy, S.J. Kwon, G.S. Park. High- $T_{c}$ superconductors in the two-dimensional limit: [ $\left.\left(\mathrm{Py}-\mathrm{C}_{n} \mathrm{H}_{2 n+1}\right)_{2} \mathrm{HgI}_{4}\right]-$ $\mathrm{Bi}_{2} \mathrm{Sr}_{2} \mathrm{Ca}_{m-1} \mathrm{Cu}_{m} \mathrm{O}_{y}(m=1$ and 2). Science 280, 1589 (1998).

2. J.H. Choy, S.Y. Kwak, J.S. Park, Y.J. Jeong, J. Portier. Intercalative nanohybrids of nucleoside monophosphates and DNA in layered metal hydroxide. J. Am. Chem. Soc. 121, 1399 (1999).

3. I.I. Grygorchak, B.O. Seredyuk, K.D. Tovstyuk, B.P. Bakhmatyuk. High Frequency Capacitor Nanostructure Formation by Intercalation (Kluwer, 2002).

4. S.A. Voitovych, I.I. Grygorchak, O.I. Aksimentyeva. Lateral semiconductive and polymer conductive nanolayered 
structures: Preparation, properties, and application. Mol. Cryst. Liq. Cryst. 497, 55 (2008)

5. J.H. Choy, S.M. Peak, J.M. Oh, E.S. Jang. Intercalative route to heterostructured nanohybrids. Curr. Appl. Phys. 2, 489 (2002).

6. J.W. Steed, J.L. Atwood. Supramolecular Chemistry (Wiley, 2000).

7. T.M. Bishchanyuk, R.Ya. Shvets', I.I. Grygorchak, S.I. Budzulyak, L.S. Yablon', I.A. Klymyshyn. Thermodynamic and kinetic features of $\mathrm{Li}^{+}$-intercalation current formation in supramolecular ensembles of hierarchical architecture based on MSM-41 and expanded graphite with carbamide cavitand. Fiz. Khim. Tverd. Tila 14, 190 (2013) (in Ukrainian).

8. I.I. Grygorchak, F,O. Ivashchyshyn, O.I. Grygorchak, D.V. Matulka. Intercalated nanostructures with hierarchical supramolecular architecture: Obtaining, properties, application Zh. Fiz. Inzh. Poverkhn. 8, 284 (2010) (in Ukrainian).

9. T.M. Bishchaniuk, I.I. Grygorchak. Colossal magnetocapacitance effect at room temperature. Appl. Phys. Lett. 104, 203104 (2014).

10. R.M.A. Lies. Preparation and Crystal Growth of Materials with Layered Structures (Springer, 1977).

11. R.H. Friend , A.D. Yoffe. Electronic properties of intercalation complexes of the transition metal dichalcogenides. Adv. Phys. 36, 1 (1987).

12. J.-M. Lehn. Supramolecular Chemistry. Concepts and Perspectives (Wiley-VCH, 1995).

13. T.M. Bishchaniuk, O.V. Balaban, R.Ya. Shvets, I.I. Grygorchak, A.V. Fechan, B.A. Lukiyanets, F.O. Ivashchyshyn. Electronic processes and energy storage in inorganic/organic nanohybrids. Mol. Cryst. Liq. Cryst. 589, 132 (2014)

14. Z.B. Stoinov, B.M. Grafov, B. Savova-Stoinova, and V.V. Elkin, Electrochemical Impedance (Nauka, 1991) (in Russian).

15. E. Barsoukov, J. R. Macdonald. Impedance Spectroscopy. Theory, Experiment and Application (Wiley, 2005).

16. M. Pollak, T.H. Geballe. Low-frequency conductivity due to hopping processes in silicon, Phys. Rev. 122, 1742 (1961)

17. M.A. Ormont. Change of transport mechanism in the transition region from sublinearity to superlinearity in the frequency dependence of the conductivity in disordered semiconductors. Fiz. Tekh. Poluprovodn. 10, 1314 (2015) (in Russian).

18. M. Okutan, E. Basaran, H.I. Bakanb, F. Yakuphanoglu. AC conductivity and dielectric properties of Co-doped $\mathrm{TiO}_{2}$. Physica B 364, 300 (2005).

19. B.I. Shklovskii, A.L. Efros. Zero-phonon ac hopping conductivity of disordered systems. Zh. Èksp. Teor. Fiz. 81, 406 (1981) (in Russian).

20. I.G. Austin, N.F. Mott. Polarons in crystalline and noncrystalline materials. Adv. Phys. 18, 41 (1969).

21. B.P. Zakharchenya, V.L. Korenev. Integrating magnetism into semiconductor electronics. Usp. Fiz. Nauk 175, 629 (2005) (in Russian).
22. I. Mora-Sero, J. Bisquert. Implications of the negative capacitance observed at forward bias in nanocomposite and polycrystalline solar cells. Nano Lett. 6, 640 (2006).

23. N.A. Penin. Negative capacitance in semiconductor structures. Fiz. Tekh. Poluprovodn. 30, 630 (1996) (in Russian).

24. J. Bisquert, H. Randriamahazaka, G. Garcia-Belmonte. Inductive behaviour by charge-transfer and relaxation in solid-state electrochemistry. Electrochim. Acta 51, 627 (2005).

25. I.V. Stasyuk, O.V. Velychko. Studies of electronic states in strongly anisotropic layered structures with staged ordering. Zh. Fiz. Dosl. 18, 2002 (2014) (in Ukrainian).

26. I.V. Stasyuk, O.V. Velychko. Description of intercalated layered structures in the approach of Anderson periodic model. Preprint ICMP-14-07U (Institute of Condensed Matter Physics, Lviv, 2014) (in Ukrainian).

27. R. Andreichin. High-field polarization, photopolarization and photoelectret properties of high-resistance amorphous semiconductors. J. Electrostat. 1, 217 (1975).

28. J.F. Fowler. X-Ray induced conductivity in insulating materials. Proc. R. Soc. Lond. A 236, 464 (1956).

29. M.H. Weiler, W. Zawadzki, B. Lax. Theory of tunneling, including photon-assisted tunneling, in semiconductors in crossed and parallel electric and magnetic fields. Phys. Rev. 163, 733 (1967).

30. M. Reine, Q.H.F. Vrehen, B. Lax. Photon-assisted magnetotunneling in germanium in parallel and crossed electric and magnetic fields. Phys. Rev. 163, 726 (1967).

31. T.M. Bishchanyuk, I.I. Grygorchak, F.O. Ivashchyshyn. Multilayered semiconductor clathrate-cavitand complexes with a fractal guest system. Fiz. Inzh. Poverkhn. 12, 360 (2014) (in Ukrainian).

Received 22.03.17.

Translated from Ukrainian by O.I. Voitenko

\section{I.I. Григорчак, О.І. Григорчак, Ф.О. Іващишин}

МОДИФІКАЦІЯ ВЛАСТИВОСТЕЙ

КЛАТРАТО/КАВІТАТНИХ КОМПЛЕКСІВ

$\mathrm{InSe}\left\langle\beta-\mathrm{CD}\left\langle\mathrm{FeSO}_{4}\right\rangle\right\rangle$ IЄPAPХIЧНОÏ AРХITЕКТУРИ

ПРИ ЇХ СИНТЕЗІ В СХРЕЩЕНИХ ЕЛЕКТРИЧНОМУ

І СВІТЛОВої ХВИЛІ ПОЛЯХ

$\mathrm{P}$ е $з$ ю м е

У роботі запропоновано новий технологічний підхід до синтезу мультишарових наноструктур, який дає можливість забезпечити їм унікальні властивості і неординарні перспективи практичного застосування. Зокрема показано, що синтез наноструктури з ієрархічною архітектурою $\operatorname{InSe}\left\langle\beta-C D\left\langle\mathrm{FeSO}_{4}\right\rangle\right\rangle$ в схрещених електричному і світлової хвилі полях спричиняє появу аномально високого додатного магніторезистивного ефекту з гігантськими осциляціями магнетоопору у низькочастотному інтервалі $10^{-3}$ 10 Гц. Обгрунтовано ефективність застосування синтезованого наногібриду як активних елементів безгіраторних наноліній затримки, керованих магнітним полем, та надчутливих сенсорів магнітного поля за кімнатних температур. 